\section{Global status report on violence prevention 2014}

The Global status report on violence prevention $2014^{1}$ describes what countries are doing to address interpersonal violence, and is a joint publication of WHO, United Nations Office on Drugs and Crime, and United Nations Development Programme. Interpersonal violence includes child maltreatment, youth violence, intimate partner violence, sexual violence and elder abuse. ${ }^{2}$ It is a leading cause of death among young people and results in millions of non-fatal injuries that receive emergency medical care. Furthermore, exposure to interpersonal violence is associated with increased health risk behaviours mental health problems, physical health problems and reproductive health problems. ${ }^{2}$

Epidemiological studies of interpersonal violence are increasing, as are outcome evaluation studies of what works to prevent it. $^{3}$ By contrast, few efforts have documented the extent to which countries are making use of scientific knowledge to design and monitor policies, programmes and laws to prevent such violence and provide services for victims. ${ }^{4-6}$

WHO has promoted a public health approach to preventing interpersonal violence since the mid-1990s, and WHO Member States have adopted several resolutions on the topic. It is against this backdrop that on 11 December 2014 the Global status report on violence prevention 2014 was launched. The report:

- describes the state of the problem of interpersonal violence worldwide and the extent to which countries are collecting data on fatal and non-fatal violence to inform action;

- assesses the current status of programme, policy and legislative measures to prevent violence;

- evaluates the availability of healthcare, social and legal services for victims of violence, and

- identifies gaps in tackling the problem of interpersonal violence and stimulates national action to address them.

In each country, with the help of a government-appointed national data coordinator, representatives from 6 to 10 sectors completed a questionnaire before convening in a consensus meeting to agree on the final country data. The questionnaire covered interpersonal violence in general, and had specific sections on child maltreatment, youth violence, intimate partner and sexual violence against women, and elder abuse. In all, 133 countries responded to the survey, representing $88 \%$ of the world's population.

The report estimates that there were 475000 homicides globally in 2012, with the highest homicide rates in central and southern America and southern Africa, and the lowest in the western Pacific and western European regions. The highest regional rates are 10 times greater than the lowest, and $82 \%$ of homicide victims are men. Between 2000 and 2012, homicide rates are estimated to have declined globally by $16 \%$ and in high-income countries by $39 \%$.

Data are essential to inform and monitor prevention programmes and service delivery, and action plans are the foundation for coherent efforts to address violence. The report shows that $60 \%$ of countries lack usable data on homicide from civil or vital registration sources.

The report reviews the existence and implementation of 18 'best buy' prevention programmes, such as parenting support programmes to prevent child maltreatment, life and social skills training to prevent youth violence, and residential care programmes to prevent elder abuse. Just a third of countries indicated they were implementing each of the best buy prevention programmes on a larger scale (eg, across many schools or communities or reaching $30 \%$ of the intended target population).

Specific prevention programmes must be complemented by society-wide policies to address the social determinants of violence, such as housing policies aimed at preventing violence by reducing concentrations of poverty. However, few countries are implementing such measures. More countries say they are tackling harmful use of alcohol, although patterns of risky drinking behaviour remain very high in several countries. Nearly all countries report measures to regulate access to firearms, although the laws themselves and the populations covered vary widely.

Concerning laws, the report describes the extent to which countries have enacted and enforced each of 12 laws. These include laws against rape, bans on corporal punishment and laws against elder abuse. The biggest gaps between enactment and enforcement of these laws related to bans on corporal punishment, and to domestic and family violence legislation, and few countries had even enacted laws against elder abuse.

Victim services are critical for reducing the harmful effects of violence and preventing repeat involvement in violence. The report finds great unevenness in the extent to which the six different services examined are being implemented. For example, while around $70 \%$ of countries indicate they have child protection services and medicolegal services for sexual violence victims, just a third indicate having adult protective services for victims of elder abuse.

Based on these and other findings, the report's five key recommendations are to: scale up evidence-informed prevention programmes; ensure full implementation of existing laws; ensure the wide availability and accessibility of victim services; strengthen the collection and use of data to inform and monitor prevention programmes, and set national, regional and global baselines and targets.

Download the report and related materials at http://www.who. int/violence_injury_prevention/violence/status_report/2014/en/

\section{Alexander Butchart, ${ }^{1}$ Christopher Mikton, ${ }^{1}$ Linda L Dahlberg, ${ }^{2}$ Etienne G Krug'}

${ }^{1}$ Management of Noncommunicable Diseases, Disability, Violence and Injury Prevention, World Health Organization, Geneva, Switzerland

2Division of Violence Prevention, National Center for Injury Prevention and Control, Centers for Disease Control and Prevention, Atlanta, Georgia, USA

Contributors The findings and conclusions in this manuscript are those of the authors and do not necessarily represent the official position of the Centers for Disease Control and Prevention.

Competing interests None declared.

Provenance and peer review Commissioned; internally peer reviewed.

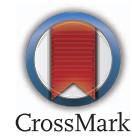

To cite Butchart A, Mikton C, Dahlberg LL, et al. Inj Prev 2015;21:213.

Received 8 April 2015

Accepted 18 April 2015

Inj Prev 2015;21:213. doi:10.1136/injuryprev-2015-041640

\section{REFERENCES}

1 World Health Organization. Global status report on violence prevention 2014. Geneva: World Health Organization, 2014.

2 Krug EG, Dahlberg LL, Mercy JA, et al. The world report on violence and health. Geneva: World Health Organization, 2002. Report No. 0140-6736.

3 Hughes $\mathrm{K}$, Bellis MA, Hardcastle KA, et al. Global development and diffusion of outcome evaluation research for interpersonal and self-directed violence prevention from 2007 to 2013: A systematic review. Aggression Violent Behav 2014; 19:655-62

4 WHO Regional Office Europe. Preventing injuries in Europe: from international collaboration to local implementation. Copenhagen: WHO Regional Office Europe, 2010.

5 Dubowitz $\mathrm{H}$, ed. World perspectives on child abuse. 10th edn. Aurora, Colorado: International Society for Prevention of Child Abuse and Neglect, 2012.

6 Special Representative of the Secretary General on Violence Against Children. Toward a world free from violence: global survey on violence against children. New York: Special Representative of the Secretary General on Violence Against Children, 2013. 